\title{
Selection of vendors for wind farm under fuzzy MCDM environment
}

\author{
Nikhil Chandra Chatterjee and Goutam Kumar Bose*
}

Department of Mechanical Engineering, Haldia Institute of Technology, Haldia, West Bengal, India

\section{H R O N I C L E}

Article history:

Received March 162013

Received in revised format

May 92013

Accepted May 302013

Available online

June 32013

Keywords:

Vendor Selection

$M C D M$

ARAS-F

COPRAS-F

Fuzzy Set Theory

Wind Farm

\section{A B S T R A C T}

Wind farms are designed to supply power to the consumers at a minimal price. The cost of wind power production directly or indirectly depends on proper selection of vendors. The present paper highlights a model for selection and ranking of vendors for a wind farm based on fuzzy set theory to determine criteria weights and an additive ratio assessment (ARAS) method to analysis criteria values. The objective of the paper is to establish the ARAS method as an effective method for Vendor selection. A case study is shown to ascertain the proposed method especially when the criteria are interdependent and conflicting in nature. The result is validated with another popular MCDM technique, COPRAS, which shows that the models are effective and applicable, and provide decision makers with better solutions for decision making.

(C) 2013 Growing Science Ltd. All rights reserved

\section{Introduction}

Commercial wind turbines are installed at wind farms, which are clusters of wind turbines grouped together for large-scale electricity generation. The steady growth on wind power capacity has increased demand for wind turbines and components for the past two decades. Strong, consistent governmental incentive policies including direct government investment, tax breaks, loans, regulations and laws have supported the development of wind turbine manufacturing companies all over the world. It is impossible for a wind farm to produce electricity at low-cost without satisfactory vendors, successfully. The selection of right vendor, i.e., wind turbine manufacturer for a wind farm should not only meet customer requirements, bring profit to the farm, but also help in fulfilling different criteria such as cost, delivery, quality objectives and technical specifications, etc. The selection of suitable vendors is one of the most essential functions of any firm's purchasing department. Over the past two decades, several studies have pointed out various techniques for selecting suitable vendors with effective evaluation criteria for the vendor selection problem.

\footnotetext{
* Corresponding author. Tel:91-9903313045

E-mail: gkbose@yahoo.com (G. K. Bose)

(c) 2013 Growing Science Ltd. All rights reserved. doi: $10.5267 /$ j.ijiec.2013.06.002
} 
Wind turbines are manufactured by original equipment manufacturers, which design, assemble, and brand their products and they are mostly system integrators. Assemblers must bring together precision parts and components to generate a wind turbine. One supplier might roll large plates of steel into the towers, which support the turbine. A second company might make the turbine blades and a third might manufacture the electronic computerized control systems. Each of these components might be produced separately and assembled from imported inputs, or might be imported as an assembled product. Many suppliers are part of this complex global supply chain. Tier 1 suppliers make large components such as towers, hubs, blades, or gearboxes. Tier 2 suppliers produce subassemblies such as ladders, fiberglass, control systems, hydraulics, power electronics, fasteners, resin, machine parts, or motors. Fuzzy Multi Criteria Decision Making (FMCDM) is an approach to deal with the inherent impression, vagueness and subjectiveness of the human decision making process effectively. It is required to develop a systematic vendor selection process for detecting and prioritizing relevant technical, economic and performance criteria. As the supplier selection problem usually involves more than one criterion and they are normally conflicting in nature, hence FMCDM model has a key role to play in order to select the suitable vendors.

A survey of previous literatures reveals a lot of published works on multiple criteria decision making (MCDM) and the selection of supplier or vendors. Zavadskas and Turskis (2010) developed Additive Ratio Assessment (ARAS) as a new MCDM technique. Zadeh (1965) introduced fuzzy set theory to solve the vagueness in information and the fuzziness of human perception. Bakshi and Sarkar (2011) implemented AHP for analysis of the structure of the project selection problem and to assign the weights of the properties and the ARAS method was used to obtain the final ranking and selecting the best one amongst the projects. Zavadskas et al. (2010) applied ARAS method to select the foundation installment alternatives.

Turskis and Zavadskas (2010b) presented a newly developed MCDM method ARAS-F to solve various problems in transport, construction, economics, technology and sustainable development. Dadelo et al. (2012) presented a model for personnel assessment and ranking, which is based on expert evaluation method to determine criteria weights and on ARAS method to aggregate criteria values. Turskis et al. (2013) applied Analytic Hierarchy Process (AHP) and ARAS-G methods to solve the problem of valuation of urban cultural heritage in the perspective of sustainable city development by considering various environment factors as well as stakeholders' needs. Yang et al. (2008) proposed integrated fuzzy analytical hierarchy process (F-AHP) based MCDM method to address vendor selection problem based on the overall aggregating score of each vendor using the fuzzy weights with fuzzy synthetic utilities.

Tahriri et al. (2008) discussed different selection methods concerning supplier selection, especially using AHP were illustrated and compared with other methods. Tsai et al. (2003) utilized the Grey Relational Analysis (GRA) to establish a compute and accurate evaluate model for selecting vendors. It reduces the purchasing cost and increases the production efficiency significantly. Ting (2004) developed a hierarchical structure of both quantitative and qualitative criteria to select suppliers through AHP and a multi-objective linear programming (MOLP) model was formulated to help the management to allocate the optimum order quantities, in which the three objectives are optimized. Total purchasing expenditure, quality and delivery reliability, and purchasing budget, production demand, suppliers' capacity, quality control and inventory control constraints were considered to supplier selection for a high technology company in Taiwan, which mainly manufactures motherboards for desktop PCs and notebook computers. Kumar et al. (2004) presented a fuzzy goal programming approach to solve the vendor selection problem with three objectives.

Bayazit (2006) proposed an ANP model to make an assessment on supplier selection process. Shyur and Shih (2006) formulated for supporting the vendor selection process by the combined use of the MCDM approach and a proposed five-step hybrid process, which incorporates the technique of 
Analytic Network Process (ANP) and then the modified Technique for Order Performance by Similarity to Idea Solution (TOPSIS) was adopted to rank competing products in terms of their overall performances. Demirtas and Ustun (2008) presented an integrated approach of ANP and MultiObjective Mixed Integer Linear Programming (MOMILP) to consider both tangible and intangible factors in choosing the best suppliers and define the optimum quantities among selected suppliers to maximize the total value of purchasing and minimize the budget and defect rate. Shahanaghi and Yazdian (2009) proposed a new fuzzy multiple criteria group decision making (FMCGDM) technique based on TOPSIS method. They evaluated and selected an appropriate vendor, where the ratings of each alternative and importance weight of each criterion were expressed in trapezoidal fuzzy numbers using the canonical representation of multiplication operation on three trapezoidal fuzzy numbers to construct the weighted normalized decision matrix.

Behnam Vahdani et al. (2009) applied AHP in obtaining criteria weights and TOPSIS along with the fuzzy set theory for obtaining final ranking of vendors. Sim et al. (2010) presented a survey report for 80 firms to identify the preference of local purchasers in selecting their suppliers in Malaysian manufacturing industries in evaluating their suppliers. Soeini et al. (2012) used the idea of the algorithm "Knapsack" to select suppliers with an attempt to take the advantage of a simple numerical method for solving any ambiguity of this model. Chatterjee et al. (2011) attempted to solve the supplier selection problem using two most potential multi-criteria decision-making (MCDM) approaches 'Vlse Kriterijumska Optimizacija Kompromisno Resenje' (VIKOR), a compromise ranking method and 'ELimination and Et Choice Translating REality' (ELECTRE) an outranking method and compares their relative performance for a given organizational environment with two real-time examples.

Turskis and Zavadskas (2010b) presented a new ARAS method with the grey criteria scores (ARAS-G) for the selection of a potential supplier, which had to be the most appropriate to stakeholders. Khaled et al. (2011) discussed some multi-criteria decision making techniques such as Linear weighted method, Categorical method, Fuzzy approach, AHP with some examples to select the best supplier selection. Lin et al. (2011) applied ANP and TOPSIS to calculate the weight and provide the suppliers a ranking and Linear Programming (LP) to allocate order quantity for each vendor in the supplier selection process.

Sadig et al. (2011) proposed an integrated approach of Multi-Attribute Utility Theory (MAUT) and Linear Programming (LP) for supplier selection problems when a buyer needs more than one product and also. They used a Mixed Integer Linear Programming (MILP) approach in a discount environment to determine the best suppliers and to place the optimal order quantities among them taken into account both cumulative and incremental discounts.

Sharma (2012) presented an efficient Fuzzy MCDM approach for quality evaluation and performance appraisal in vendor selection. Kim and Wagner (2012) discussed how the conventional decision models of supplier selection should be extended. They considered the fact that supplier configuration requires supplier selection for each subsystem of a product and then highlighted the need to consider interrelationships between suppliers, during the selection process of the combination of suppliers introducing the supplier configuration graph in order to provide a clear picture of the problem.

Singh (2012) applied the methodology for selection of suppliers was based upon multiple criteria decision making method using TOPSIS and application of TOPSIS proved to be a powerful technique for performance evaluation, comparative assessment and selection of supplier(s). Jayaswal et al. (2012) developed a fuzzy Multi Criteria Decision Making method to select suitable vendor. Mirahmadi and Teimoury (2012) selected suppliers based on fuzzy VIKOR model with trapezoidal fuzzy numbers to overcome ambiguity of evaluation process. In order to reduce risk and cost, they used a Kraljic matrix to classify items based on criteria and then determined the overall supply strategies. 
Datta and Mahapatra (2012) demonstrated the effectiveness of two MCDM approaches, utility concept and VIKOR method to solve the problems through a case study of vendor selection. They also compared the results with grey relation technique and found that the utility theory was quite straightforward and free from computational complexity compared with grey relation theory as well as VIKOR method. Lee (2012) combined fuzzy and grey theories to develop a multi-criteria decisionmaking model to deal with problems regarding supplier selection.

Haldar et al. (2012) presented a four tier process for supplier selection, initially determined the supplier's using the TOPSIS and AHP methodology for general selection criteria and assigned a cut-off value for the supplier weight weights for the primary selection process. Using AHP-QFD methodology the manufacturer's critical criteria and resiliency criteria are integrated into the selection process, to determine the subjective factor measures for each of the primary selected suppliers. They united separate cost factors by using a normalizing technique to determine the objective factor measure for each of the suppliers and finally, a supplier selection index is calculated in which the decision maker's attitude plays an important role.

Dey et al. (2012) proposed a novel multidisciplinary technique based on fuzzy- MOORA (Multiple Objective Optimization on the Basis of Ratio Analysis) for making decisions regarding selection of vendors. Zavadskas and Kaklauskas (1996) introduced COPRAS (COmplex PRoportional ASsessment). Zavadskas and Antucheviciene (2007) applied fuzzyfied COPRAS method to analyze the regeneration alternatives of derelict buildings in rural areas at Lithuania.

In this paper, ARAS method is used because the utility function value of a feasible alternative is directly proportional to the relative effect of values and weights of the main criteria considered for the vendor selection problem and as well as the deviation from an optimal alternative can be visible. The results are validated by applying COPRAS. The paper is organized as follows: Section 2 presents proposed algorithm, in the section 3, a case study of wind turbine vendor selecting problem is furnished and solved along with a Discussion in section 4. Finally significant concluding remarks are drawn in section 5 on the proposed model.

\section{Methodology}

Decision-making is the scientific and logical process of the selection of a course of action from among two or more possible alternatives in order to choose a solution for a given problem (Trewatha \& Newport, 1982). When there is only one criterion in each alternative, the problem is known as single criterion decision making problem, whereas the problem consists of a finite number of criteria the problem belongs to the field of multi criteria decision making (MCDM) problems. The single criterion decision making problem is less complicated because decision can be made implicitly by determining the alternative with the best value of the single criterion. Where MCDM is the method, which concerns about multiple conflicting criteria can be formally incorporated into the management planning process. Hwang and Yoon (1981) have classified the MCDM problem into two types, i.e., multi-attribute decision-making (MADM) and multi-objective decision-making (MODM). MADM concerns with selection of the suitable alternative based on prioritized attributes of the alternatives from a set of alternatives, whereas MODM concerns with optimization of an alternative or alternatives on the based on preferences of objectives.

\subsection{Fuzzy Set Theory}

There are many cases where decision maker (DM) is not able to assign a crisp value to an event and DM can only expresses his/her insight in terms of linguistic terms. Decision matrix can be converted into a fuzzy decision matrix and a weighted normalized fuzzy decision matrix can be constructed after 
the decision makers' fuzzy ratings have been completed. In a universe of discourse X, a fuzzy set $\tilde{d}$ is characterized by a membership function $\mu_{\tilde{d}}(x)$, i.e., degree of membership of $\mathrm{x}$ in $\tilde{d}$ where maps each element $x$ in $X$ to a real number in the interval $[0,1]$. A triangular fuzzy number (TFN), $\tilde{d}$ can be defined as a triplet $\left(d_{1}, d_{2}, d_{3}\right)$ and the membership function is defined (Dubois \& Prade 1978, Keufmann and Gupta 1991) as shown by Eq. (1).

$\mu_{d}(x)= \begin{cases}0, & x \leq d_{1} \\ \frac{x-d_{1}}{d_{2}-d_{1}}, & \mathrm{~d}_{1} \leq x \leq d_{2} \\ \frac{d_{3}-x}{d_{3}-d_{2}}, & \mathrm{~d}_{2} \leq x \leq d_{3} \\ 0, & x>\mathrm{d}_{3}\end{cases}$

The above equation can also be depicted in Fig. 1. The conversion technique of fuzzy number into nonfuzzy number, i.e., crisp value is known as defuzzyfication. In this paper, we use 'centre of area' technique for determining Best Non-fuzzy Performance (BNP) value.

$$
B N P=\frac{\left[\left(d_{3}-d_{1}\right)-\left(d_{2}-d_{1}\right)\right]}{3}+d_{1}
$$

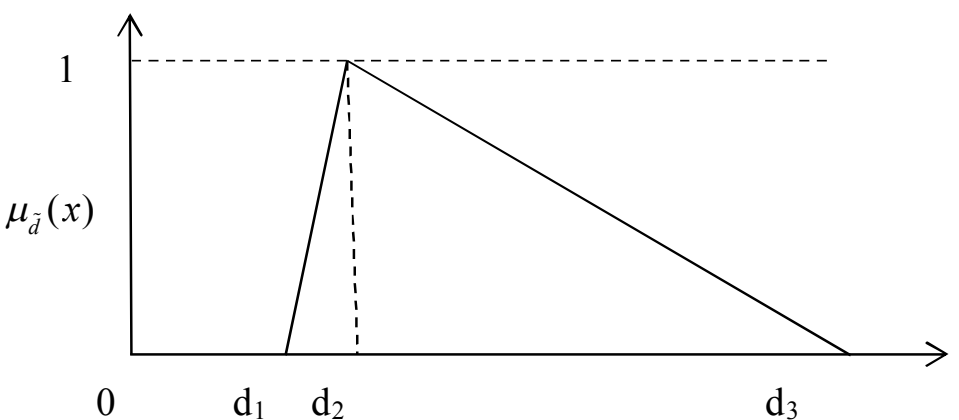

Fig. 1. Membership function of a triangular fuzzy number $\tilde{d}=\left(d_{1}, d_{2}, d_{3}\right)$

\subsection{ARAS-F}

Additive Ratio ASsessment (ARAS) method logically compared that the ratio of the sum of normalized and weighted values of criteria, which describe available alternative, to the sum of the values of normalized and weighted criteria, which describes the optimal alternative, is degree of optimality, which is reached by the alternative under comparison.

The steps for solving the problems are depicted (Turskis \& Zavadskas, 2010b) as follows:

Step-1: Initialization of decision-making: Generation of feasible alternatives $(m)$, Determination of the evaluation criteria $(n)$.

Step-2: Choosing the linguistic ratings for criteria and alternatives: The importance weights of various criteria and alternatives are considered as linguistic variables. These linguistic variables can be expressed in positive triangular fuzzy numbers as Tables 1 . 
Table 1

Linguistic terms for criteria \& alternatives

\begin{tabular}{lccc}
\hline & Criteria & & \multicolumn{2}{c}{ Alternatives } \\
Linguistic terms & Fuzzy number & Linguistic terms & Fuzzy number \\
\hline Extremely Important (VVI) & $(0.9,1.0,1.0)$ & Very Good (VG) & $(0.9,1.0,1.0)$ \\
Very Important (VI) & $(0.7,0.9,1.0)$ & Good (G) & $(0.7,0.9,1.0)$ \\
Important (I) & $(0.5,0.7,0.9)$ & Medium Good (MG) & $(0.5,0.7,0.9)$ \\
Moderate Important (MI) & $(0.3,0.5,0.7)$ & Medium (M) & $(0.3,0.5,0.7)$ \\
Moderate Unimportant (MU) & $(0.1,0.3,0.5)$ & Medium Poor (MP) & $(0.1,0.3,0.5)$ \\
Unimportant (U) & $(0.0,0.1,0.3)$ & Poor (P) & $(0.0,0.1,0.3)$ \\
Most Unimportant (MoU) & $(0.0,0.0,0.1)$ & Very Poor (VP) & $(0.0,0.0,0.1)$ \\
\hline
\end{tabular}

Step-3: Formation of the decision-making matrix: The fuzzy decision-making matrix is formed as in Eq. (3)

$$
\begin{aligned}
& \text { Alternatives } \quad \text { Criteria } \rightarrow \\
& \downarrow C_{1} \quad C_{j} \quad C_{n} \\
& \tilde{D}=\begin{array}{c}
A_{0} \\
A_{1} \\
\vdots \\
A_{i} \\
\vdots \\
A_{m}
\end{array}\left[\begin{array}{ccccc}
\tilde{d}_{01} & \ldots & \tilde{d}_{0 j} & \ldots & \tilde{d}_{0 n} \\
\tilde{d}_{11} & \ldots & \tilde{d}_{1 j} & \ldots & \tilde{d}_{1 n} \\
\vdots & \ldots & \vdots & \ldots & \vdots \\
\tilde{d}_{i 1} & \ldots & \tilde{d}_{i j} & \ldots & \tilde{d}_{i n} \\
\vdots & \ldots & \vdots & \ldots & \vdots \\
\tilde{d}_{m 1} & \cdots & \tilde{d}_{m j} & \ldots & \tilde{d}_{m n}
\end{array}\right]
\end{aligned}
$$

In which element $\tilde{d}_{i j}$ i.e., $\left[\tilde{d}_{i j 1}, \tilde{d}_{i j 2}, \tilde{d}_{i j 3}\right]$ indicates the parameter of alternative $A_{i}$ with the decision criterion $C_{j}$ (for $i=0,1,2,3, \ldots, m$, and $j=1,2,3, \ldots, n$ ) and $\tilde{d}_{0 j}$ indicates optimal value of $j$ criterion.

If optimal value of $j$ criterion is unknown, then

$$
\tilde{d}_{o j}=\left\{\begin{array}{l}
\max _{\mathrm{i}} \tilde{d}_{i j}, \text { if } \max _{\mathrm{i}} \tilde{d}_{i j} \text { is preferable } \\
\min _{\mathrm{i}} \tilde{d}_{i j}^{*}, \text { if } \min _{\mathrm{i}} \tilde{d}_{i j}^{*} \text { is preferable }
\end{array}\right.
$$

The performance values of $d_{i j}$ and the criteria weights $q_{j}$ are viewed in the entries of a decision matrix. The weights of criteria are determined by using fuzzy set theory. Defuzzified the fuzzy weight of each criterion $\left(w_{1}, w_{2}, w_{3}\right)$ into crisp values $\left(w_{j}\right)$ by using the Eq. (5).

$$
w_{j}=\frac{\left[\left(w_{3}-w_{1}\right)-\left(w_{2}-w_{1}\right)\right]}{3}+w_{1}
$$

Now the weight $q_{j}$ of $j^{\text {th }}$ criterion is computed as follow.

$$
q_{j}=\frac{w_{j}}{\sum_{j=i}^{n} w_{j}}
$$

So that, $\sum q_{j}=1$

\section{Step-3: Defuzzifying the fuzzy decision matrix:}

Defuzzification of the fuzzy decision matrix into crisp values by using the Eq. (2).

\section{Step-4: Normalization of defuzzified decision matrix $(\bar{D})$ :}

The objective of normalization is to obtain comparable scales of criteria values. The normalization of criteria values is not compulsory, but it may be required sometimes. In order to avoid the difficulties caused by different dimensions of the criteria values, the ratio to the optimal value is used [Zavadskas $\&$ Turskis, 2008]. The normalized value $\bar{d}_{i j}$ is calculated whose maximum value of $d_{i j}$ is preferable, using the Eq. (7); 
$\bar{d}_{i j}=\frac{d_{i j}}{\sum_{i=0}^{m} d_{i j}}$

The criteria, whose minimum values are preferable, are normalized by applying two-stage procedure, using the Eq. (8);

$$
d_{i j}=\frac{1}{d_{i j}^{*}} \text { and } \bar{d}_{i j}=\frac{d_{i j}}{\sum_{i=0}^{m} d_{i j}}
$$

Step-5: Formation of the Weighted Normalized Decision Matrix $(D)$ : The weighted normalized decision value $(\hat{d})$ is calculated using Eq. (9).

$$
\hat{d}_{i j}=\bar{d}_{i j} \times q_{j} \quad(0 \leq i \leq m, \quad 1 \leq j \leq n)
$$

Step-7: Determining values of optimality function of $i$ alternative $\left(S_{i}\right)$ : The sum of criteria measures can be calculated by following equation.

$S_{i}=\sum_{j=1}^{n} \hat{d}_{i j}, \quad$ where $0 \leq i \leq m$

The biggest value is the best and as well as the lowest one is the worst.

Step 8: Ranking: The ranking of the alternatives can be determined according to the value $S_{i}$. Then, the alternative with the highest score is selected as the preferred (best) one.

Step 9: Computation of degree of the alternative utility $\left(K_{i}\right)$ : The degree of the alternative utility is determined by a comparison of the variant, which is analyzed, with the ideally best one $S_{0}$. The Eq. (11) used for the calculation of the utility degree of the alternative $A_{i}$.

$K_{i}=\frac{S_{i}}{S_{0}}, \quad$ where $0 \leq i \leq m$

The complex relative efficiency of the feasible alternative can be determined according to the utility function values

\subsection{COPRAS-F}

The COPRAS is one of the well-known MCDM methods, which select the best alternative among a lot of feasible alternatives by determining a solution with direct and proportional ratio to the best solution to the ratio with the ideal-worst solution. In classical COPRAS, the criteria weights and the alternatives ratings are taken into account as crisp numerical data. However, in reality the crisp data are insufficient to handle the problems of decision making under uncertainty and on the other hand exact crisp data are not easily available. These make the decision-making problems erroneous and inaccurate. COPRAS-F is applicable where criteria weights and alternative ratings are given by linguistic terms that are addressed using fuzzy numbers (triangular or trapezoidal). The steps for solving the problems are depicted (Yazdani et al., 2011; Baležentis et al., 2012) as follows:

Step-1: Initialization of decision-making: Generation of feasible alternatives $(m)$, Determination of the evaluation criteria $(n)$.

Step-2: Choosing the linguistic ratings for criteria and alternatives: The importance weights of various criteria and alternatives are considered as linguistic variables. These linguistic variables can be expressed in positive triangular fuzzy numbers as Table-1.

Step-3: Formation of the decision matrix: The fuzzy decision matrix is formed as in Eq. (12) 


$$
\begin{aligned}
& \text { Alternatives } \quad \text { Criteria } \rightarrow \\
& \downarrow C_{1} \quad C_{j} \quad C_{n} \\
& \tilde{D}=\begin{array}{c}
A_{0} \\
A_{1} \\
\vdots \\
A_{i} \\
\vdots \\
A_{m}
\end{array}\left[\begin{array}{ccccc}
\tilde{d}_{01} & \ldots & \tilde{d}_{0 j} & \ldots & \tilde{d}_{0 n} \\
\tilde{d}_{11} & \ldots & \tilde{d}_{1 j} & \ldots & \tilde{d}_{1 n} \\
\vdots & \ldots & \vdots & \ldots & \vdots \\
\tilde{d}_{i 1} & \ldots & \tilde{d}_{i j} & \ldots & \tilde{d}_{i n} \\
\vdots & \ldots & \vdots & \ldots & \vdots \\
\tilde{d}_{m 1} & \ldots & \tilde{d}_{m j} & \ldots & \tilde{d}_{m n}
\end{array}\right]
\end{aligned}
$$

In which element $\tilde{d}_{i j}$ i.e., $\left[\tilde{d}_{i j 1}, \tilde{d}_{i j 2}, \tilde{d}_{i j 3}\right]$ indicates the parameter of alternative $A_{i}$ with the decision criterion $C_{j,}($ for $i=0,1,2,3, \ldots, m$, and $j=1,2,3, \ldots, n)$

\section{Step-4 Defuzzifying the fuzzy decision matrix:}

Defuzzification of the fuzzy decision matrix into crisp values by using the Eq. (2).

\section{Step-5: Normalization of defuzzified decision matrix $(\bar{D})$ :}

The objective of normalization is to obtain comparable scales of criteria values. The normalization of criteria values is not compulsory, but it may be required sometimes. In order to avoid the difficulties caused by different dimensions of the criteria values, the ratio to the optimal value is used. The normalized criteria values are determined either on the interval [0 to 1] or the interval [0 to $\infty$ ] (Zavadskas \& Turskis, 2008). The normalized value $\bar{d}_{i j}$ is calculated using the Eq. (12);

$$
\bar{d}_{i j}=\frac{d_{i j}}{\sqrt{\sum_{i=1}^{m} d_{i j}}} \quad(1 \leq i \leq m, \quad 1 \leq j \leq n)
$$

\section{Step-6: Computation of the criteria weight:}

Defuzzify the fuzzy weight of each criterion $\left(w_{1}, w_{2}, w_{3}\right)$ into crisp values $\left(w_{j}\right)$ by using the Eq. (13).

$$
w_{j}=\frac{\left[\left(w_{3}-w_{1}\right)-\left(w_{2}-w_{1}\right)\right]}{3}+w_{1}
$$

Compute of the Weight $q_{j}$ of $j^{\text {th }}$ criterion is as follow.

$$
q_{j}=\frac{w_{j}}{\sum_{j=i}^{n} w_{j}}
$$

Step-7: Formation of the Weighted Normalized Decision Matrix $(\hat{D})$ : The weighted normalized decision value $(\hat{d})$ is calculated using Eq. (15).

$$
\hat{d}_{i j}=\bar{d}_{i j} \times q_{j} \quad(1 \leq i \leq m, \quad 1 \leq j \leq n)
$$

Step-8: Calculation of the sums of weighted normalized criteria values $\left(P_{i}\right)$ for each alternative whose higher values are more preferable using Eq. (16)

$$
P_{i}=\sum_{j=1}^{l} \hat{d}_{i j}
$$

Where $l$ is the number of criteria value, which must to be maximized.

Step-9: Calculation of the sums of weighted normalized criteria values $\left(R_{i}\right)$ for each alternative whose lower values are more preferable using Eq. (17)

$$
R_{i}=\sum_{j=l}^{m} \hat{d}_{i j}
$$


where $(m-l)$ is the number of criteria values, which should be minimized.

Step-10: Calculation of the minimal value of $R_{i}$ i.e. $R_{\min }$

Step-11: Calculation of the relative weight of each alternative $\left(Q_{i}\right)$, using Eq. (18)

$$
Q_{i}=P_{i}+\frac{R_{\min } \sum_{i=1}^{n} R_{i}}{R_{i} \sum_{i=1}^{n} \frac{R_{\min }}{R_{i}}}=P_{i}+\frac{\sum_{i=1}^{n} R_{i}}{R_{i} \sum_{i=1}^{n} \frac{1}{R_{i}}}=P_{i}+\frac{1}{\frac{R_{i}}{\sum_{i=1}^{n} R_{i}} \sum_{i=1}^{n} \frac{1}{R_{i}}}=P_{i}+\frac{1}{\overline{R_{i}} \sum_{i=1}^{n} \frac{1}{R_{i}}}
$$

where, $\overline{R_{i}}=$ Normalized value of $R_{i}($ Podvezko, 2011).

$$
\overline{R_{i}}=\frac{R_{i}}{\sum_{i=1}^{n} R_{i}}
$$

Step-12: Calculation of the optimality criterion $(\boldsymbol{K})$, i.e., maximum of $Q_{i}$, i.e., $\left(Q_{\max }\right)$

Step-13: Ranking the alternatives in descending order of optimality criterion $(K)$. Then, the alternative with the highest score is selected as the preferred (best) one.

Step-14: Calculation of the utility degree $N_{i}$ of each alternative, using Eq. (20) showing, as a percentage, to compare the alternative is better or worse than other alternatives.

$$
N_{i}=\frac{Q_{i}}{Q_{\max }} \times 100 \%
$$

\section{Case Study: Wind Turbine Vendor Selection}

The purposed methodology allows the decision maker to rank the suitable vendor for a wind farm on the basis of different decision criteria in a more realistic way. To select the best vendor among V1, V2, V3, V4 and V5, twenty four criteria are selected as listed in Table -2 . The criteria weight is calculated using Eq. (5) and (6). The Result is tabulated in Table 2.

\begin{tabular}{|c|c|c|c|c|}
\hline Criteria & & Linguistic terms & $\begin{array}{c}\text { Fuzzy number } \\
\left(w_{1}, w_{2}, w_{3}\right)\end{array}$ & $q_{j}$ \\
\hline $\mathrm{C} 1$ & Must fulfill the required standard quality and specifications & VVI & $0.9,1 \cdot 0,1.0$ & 0.055 \\
\hline $\mathrm{C} 2$ & Durability of Product & VVI & $0.9,1.0,1.0$ & 0.055 \\
\hline $\mathrm{C} 3$ & Rejection rate & VI & $0.7,0.9,1.0$ & 0.050 \\
\hline $\mathrm{C} 4$ & ISO Certified Organization & VI & $0.7,0.9,1.0$ & 0.050 \\
\hline C5 & Product certification & VVI & $0.9,1.0,1.0$ & 0.055 \\
\hline C6 & Product test report from national accredited organization & VVI & $0.9,1.0,1.0$ & 0.055 \\
\hline $\mathrm{C} 7$ & Delivery schedule & VI & $0.7,0.9,1.0$ & 0.050 \\
\hline $\mathrm{C} 8$ & Reliable delivery method & MI & $0.3,0.5,0.7$ & 0.029 \\
\hline C9 & Transit Insurance & MI & $0.3,0.5,0.7$ & 0.029 \\
\hline $\mathrm{C} 10$ & Warranty/ After sale services & I & $0.5,0.7,0.9$ & 0.040 \\
\hline $\mathrm{C} 11$ & Responsiveness & MI & $0.3,0.5,0.7$ & 0.029 \\
\hline $\mathrm{C} 12$ & Company background & VI & $0.7,0.9,1.0$ & 0.050 \\
\hline $\mathrm{C} 13$ & Strategic organization structure & MI & $0.3,0.5,0.7$ & 0.029 \\
\hline $\mathrm{C} 14$ & Geographical location & I & $0.5,0.7,0.9$ & 0.040 \\
\hline $\mathrm{C} 15$ & Financial position & I & $0.5,0.7,0.9$ & 0.040 \\
\hline $\mathrm{C} 16$ & Performance history of the equipment & VI & $0.7,0.9,1.0$ & 0.050 \\
\hline $\mathrm{C} 17$ & desire for business & I & $0.5,0.7,0.9$ & 0.040 \\
\hline $\mathrm{C} 18$ & Attitude & MI & $0.3,0.5,0.7$ & 0.029 \\
\hline C19 & Impression & MI & $0.3,0.5,0.7$ & 0.029 \\
\hline $\mathrm{C} 20$ & Past business Credentials & VI & $0.7,0.9,1.0$ & 0.050 \\
\hline $\mathrm{C} 21$ & Price & VI & $0.7,0.9,1.0$ & 0.050 \\
\hline $\mathrm{C} 22$ & Distribution \& Logistic Cost & I & $0.5,0.7,0.9$ & 0.040 \\
\hline $\mathrm{C} 23$ & Discount for Bulk Order & MI & $0.3,0.5,0.7$ & 0.029 \\
\hline $\mathrm{C} 24$ & Discount for Early Payment & MI & $0.3,0.5,0.7$ & 0.029 \\
\hline
\end{tabular}

\section{Table 2}

Criteria and criteria weights

The decision matrix is tabulated in Table-3 in linguistic terms. The maximizing criteria are denoted by $(+)$ sign and the minimizing criteria are denoted by (-) sign. 
Table 3

Linguistic Decision-making Matrix

\begin{tabular}{llllllllllllllllllllllllllllllll}
\hline & C1 & C2 & C3 & C4 & C5 & C6 & C7 & C8 & C9 & C10 & C11 & C12 & C13 & C14 & C15 & C16 & C17 & C18 & C19 & C20 & C21 & C22 & C23 & C24 \\
\hline & + & + & - & + & + & + & + & + & + & + & + & + & + & + & + & + & + & + & + & + & - & - & + & + \\
$q_{i}$ & 0.055 & 0.055 & 0.05 & 0.05 & 0.055 & 0.055 & 0.05 & 0.029 & 0.029 & 0.04 & 0.029 & 0.05 & 0.029 & 0.04 & 0.04 & 0.05 & 0.04 & 0.029 & 0.029 & 0.05 & 0.05 & 0.04 & 0.029 & 0.029 \\
V0 & VG & VG & VP & VG & VG & VG & VG & VG & VG & VG & VG & VG & VG & VG & VG & VG & VG & VG & VG & VG & VP & VP & VG & MG \\
V1 & VG & G & VP & VG & G & G & VG & VG & G & MG & G & VG & VG & VP & VG & VG & VG & VG & VG & VG & VP & VG & G & M \\
V2 & VG & VG & P & VG & VG & VG & G & VG & G & G & G & G & G & P & VG & G & VG & VG & VG & G & P & VG & G & M \\
V3 & VG & G & P & VG & VG & G & MG & G & VG & VG & VG & VG & G & G & G & G & MG & MG & MG & G & MP & P & M & M \\
V4 & VG & MG & VP & VG & G & VG & VG & MG & MG & VG & G & VG & VG & VG & MG & MG & G & G & G & MG & VP & VP & VG & MG \\
V5 & VG & G & MP & VG & VG & VG & G & VG & G & VG & VG & G & VG & MG & VG & VG & VG & VG & VG & VG & MP & M & M & M \\
\hline
\end{tabular}

The defuzzyfied decision matrix is tabulated in Table-4 using Eq. (2).

Table 4

Defuzzyfied Decision Matrix

\begin{tabular}{lllllllllllllllllllllllllll}
\hline & C1 & C2 & C3 & C4 & C5 & C6 & C7 & C8 & C9 & C10 & C11 & C12 & C13 & C14 & C15 & C16 & C17 & C18 & C19 & C20 & C21 & C22 & C23 & C24 \\
\hline & + & + & - & + & + & + & + & + & + & + & + & + & + & + & + & + & + & + & + & + & - & - & + & + \\
$q_{j}$ & 0.055 & 0.055 & 0.05 & 0.05 & 0.055 & 0.055 & 0.05 & 0.029 & 0.029 & 0.04 & 0.029 & 0.05 & 0.029 & 0.04 & 0.04 & 0.05 & 0.04 & 0.029 & 0.029 & 0.05 & 0.05 & 0.04 & 0.029 & 0.029 \\
V0 & 0.97 & 0.97 & 0.03 & 0.97 & 0.97 & 0.97 & 0.97 & 0.97 & 0.97 & 0.97 & 0.97 & 0.97 & 0.97 & 0.97 & 0.97 & 0.97 & 0.97 & 0.97 & 0.97 & 0.97 & 0.03 & 0.03 & 0.97 & 0.70 \\
V1 & 0.97 & 0.87 & 0.03 & 0.97 & 0.87 & 0.87 & 0.97 & 0.97 & 0.87 & 0.70 & 0.87 & 0.97 & 0.97 & 0.03 & 0.97 & 0.97 & 0.97 & 0.97 & 0.97 & 0.97 & 0.03 & 0.97 & 0.87 & 0.50 \\
V2 & 0.97 & 0.97 & 0.13 & 0.97 & 0.97 & 0.97 & 0.87 & 0.97 & 0.87 & 0.87 & 0.87 & 0.87 & 0.87 & 0.13 & 0.97 & 0.87 & 0.97 & 0.97 & 0.97 & 0.87 & 0.13 & 0.97 & 0.87 & 0.50 \\
V3 & 0.97 & 0.87 & 0.13 & 0.97 & 0.97 & 0.87 & 0.70 & 0.87 & 0.97 & 0.97 & 0.97 & 0.97 & 0.87 & 0.87 & 0.87 & 0.87 & 0.70 & 0.70 & 0.70 & 0.87 & 0.30 & 0.13 & 0.50 & 0.50 \\
V4 & 0.97 & 0.70 & 0.03 & 0.97 & 0.87 & 0.97 & 0.97 & 0.70 & 0.70 & 0.97 & 0.87 & 0.97 & 0.97 & 0.97 & 0.70 & 0.70 & 0.87 & 0.87 & 0.87 & 0.70 & 0.03 & 0.03 & 0.97 & 0.70 \\
V5 & 0.97 & 0.87 & 0.30 & 0.97 & 0.97 & 0.97 & 0.87 & 0.97 & 0.87 & 0.97 & 0.97 & 0.87 & 0.97 & 0.70 & 0.97 & 0.97 & 0.97 & 0.97 & 0.97 & 0.97 & 0.30 & 0.50 & 0.50 & 0.50 \\
\hline
\end{tabular}

Now using Eqs. (7), (8), (9), (10) and (11) we get the final result as tabulated in Table-5.

Table 5

Final Result

\begin{tabular}{ccccc}
\hline & $S_{i}$ & $K_{i}$ & ARAS Rank & COPRAS Rank \\
\hline V0 & 0.202 & 1.0000 & & 2 \\
V1 & 0.167 & 0.8274 & 2 & 5 \\
V2 & 0.147 & 0.7288 & 5 & 4 \\
V3 & 0.148 & 0.7311 & 4 & 1 \\
V4 & 0.186 & 0.9210 & 1 & 3 \\
\hline
\end{tabular}

\section{Discussions}

According to the given data as shown in Table 5 the criteria describing the vendor selection problem for a wind farm, the priority order of the vendors is $\mathrm{V} 4>\mathrm{V} 1>\mathrm{V} 5>\mathrm{V} 3>\mathrm{V} 2$ following ARAS. It is observed that the ranking obtained by using COPRAS is also same. It suggests that the best vendor is V4 who makes 92 percent of optimality and the worst vendor is V2 who makes approximate 73 percent of optimality. The distribution of degree of the alternative utility is depicted in Fig. 2.

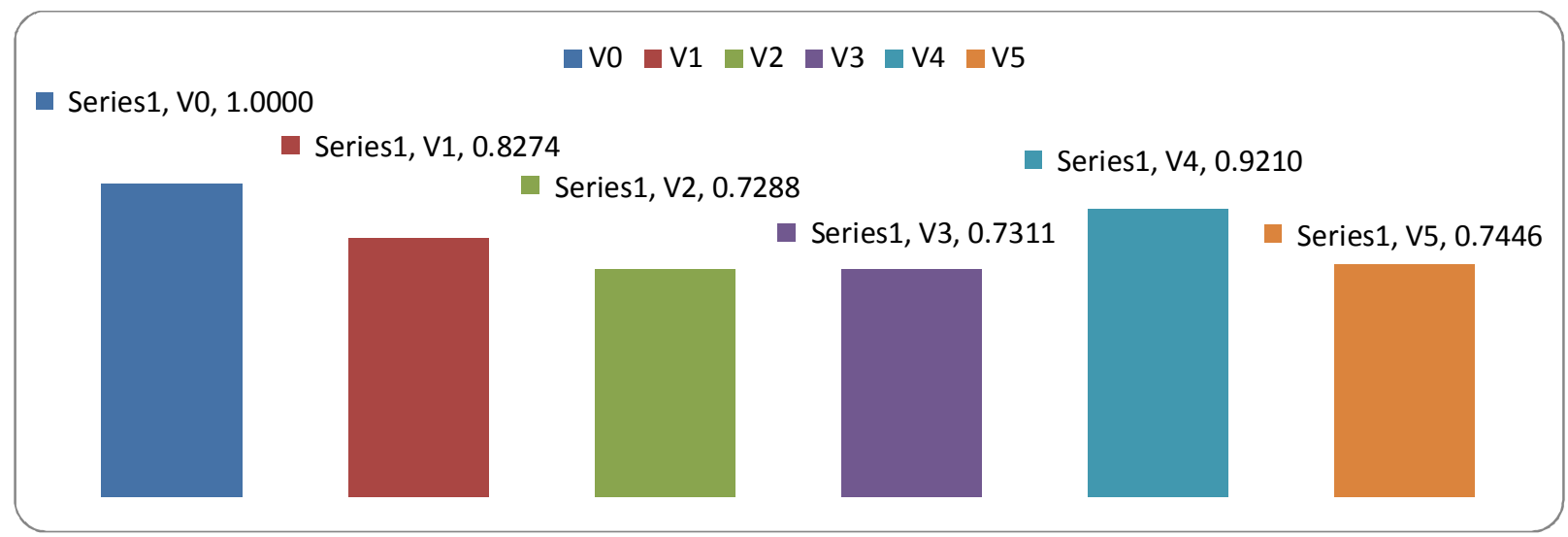

Fig. 2. The distribution of degree of the alternative utility 


\section{Conclusions}

The MCDM model has been described in this paper and applied to a wind farm to select the suitable vendor or prepare a list of vendors according to their effectiveness. The selection of vendors is an important decision for many organizations. Such decisions may greatly affect an organization's ability to compete in the market and to maintain its product quality. Vendor selection decisions also affect the ability of the organization to effectively implement production strategies. A study has been carried out in the wind power sector to prove the practical feasibility of the fuzzy ARAS method for the vendor ranking/selection problem to make a choice between suppliers on the basis of very relevant criteria. The results obtained using ARAS is validated by applying COPRAS method. The rankings of both the methods are indifferent in nature. This algorithm can be easily implemented with a spreadsheet package and its computation is fast. Therefore, the proposed model can be applied easily in practical situations. Furthermore, in the mathematical model, the weights of the criteria are determined by using fuzzy set theory. Moreover, the researchers may use some additional factors like attitude, impression, desire for business, responsiveness etc., as essential criteria for the vendor selection process.

\section{References}

Bakshi, T., \& Sarkar, B. (2011). MCA based performance evaluation of project selection, International Journal of Software Engineering \& Applications, 2(2), 14-22.

Bayazit, O. (2006). Use of analytic network process in vendor selection decisions, Benchmarking: An International Journal, 13(5), 566-579.

Dadelo, S., Turskis, Z., Zavadskas, E., \& Dadeliene, R. (2012). Multiple criteria assessment of elite security personal on the basis of ARAS and expert methods. Journal of Economic Computation and Economic Cybernetics Studies and Research, 4, 65-88.

Datta, S., \& Mahapatra, S.S. (2010). Comparative study on application of utility concept and VIKOR method for vendor selection. AIMS International Conference on Value-based Management August 11$13,614-622$.

Dey, B., Bairagi, B., Sarkar, B., \& Sanyal, S. (2012). Applications of MOORA method in vendor selection under supply chain environment, Proceedings of International Conference on Advances in Mechanical Engineering and its Interdisciplinary Areas (ICAMEI-2012).

Dey, B., Bairagi, B., Sarkar, B., \& Sanyal, S. (2012). A MOORA based fuzzy multi-criteria decision making approach for supply chain strategy selection.International Journal of Industrial Engineering Computations, 3(4), 649-662.

Chatterjee, P., Mukherjee, P., \& Chakraborty, S., (2011). Supplier selection using Compromise Ranking and Outranking Methods. Journal of Industrial Engineering International, 7(14), 61-73.

Demirtas, E.A., \& Üstün, O. (2008), An integrated multiobjective decision making process for supplier selection and order allocation, Omega, 36, 76- 90.

Dubois, D., \& Prade, H. (1978). Operations on fuzzy numbers. International Journal of Systems Science, 9 , 613-626.

Haldar, A., Ray, A., Banerjee, D., \& Ghosh, S., (2012), A hybrid MCDM model for resilient supplier selection, International Journal of Management Science and Engineering Management, 7(4), 284-292.

Hwang, C.L., \& Yoon, K. (1981). Multiple Attribute Decision Making Methods and Applications. New York: Springer-Verlag

Jayaswal, P., Trivedi, M.K., \& Kumar, L. (2012), Vendor selection methodology based on multi criteria decision making. International Journal of Interscience Management Review, 2(2), 40-45.

Khaled, A.A., Paul, S.K., Chakraborty, R.K., \& Ayuby, Md. S. (2011), Selection of suppliers through different multi-criteria decision making techniques, Global Journal of Management and Business Research, 11(4)1, 1-12.

Kim, D.Y., \& Wagner, S.M. (2012). Supplier selection problem revisited from the perspective of product configuration. International Journal of Production Research, 50(11), 2864-2876.

Keufmann, A., \& Gupta, M.M. (1991). Introduction to Fuzzy Arithmetic: Theory and Application, New York: Van Nostrand Reinhold. 
Lee, H.-L. (2012). Applying fuzzy and grey theory to multi-criteria decision-making model for supplier selection: A corporate social responsibility perspective, African Journal of Business Management, 6 (29), 8504-8514.

Lin, C.-T., Chen, B.-C., \& Ting, Y.-C. (2011). An ERP model for supplier selection in electronics industry. Expert Systems with Applications, 38, 1760-1765.

Mirahmadi, N., \& Teimoury, E. (2012). A fuzzy VIKOR model for supplier selection and evaluation: Case of EMERSUN company. Journal of Basic and Applied Scientific Research, 2(5), 5272-5287.

Podvezko, V. (2011). The comparative analysis of MCDA methods SAW and COPRAS. Inzinerine Ekonomika-Engineering Economics, 22(2), 134-146.

Sadig, A.S., Fallah. H., Chaharsooghi, S.K., Eskandari, H.R., \& Jolai, F. (2011). An integrated method for supplier selection in a multi-product and quantity discount environment. Journal of American Science, 7(10), 553-560.

Shahanaghi, K., \& Yazdian, S.A. (2009), Vendor selection using a new fuzzy group TOPSIS approach. Journal of Uncertain Systems, 3(3), 221-231.

Sharma, H.K. (2012). A fuzzy logic multi-criteria decision approach for vendor selection manufacturing system. International Journal of Modern Engineering Research, 2(6), 4189-4194.

Shyur, H.J., \& Shih, H.S. (2006). A hybrid MCDM model for strategic vendor selection. Mathematical and Computer Modelling, 44 (8), 749-761.

Singh, A.P. (2012). Supplier selection using MCDM method in TV manufacturing organization. Global Journal of Researches in Engineering, 12(1), 1-9.

Sim, H.K., Omar, Md. K., Chee, W.C., \& Gan, N. T. (2010). A survey on supplier selection criteria in the manufacturing industry in Malaysia. The 11th Asia Pacific Industrial Engineering and Management Systems Conference, Melaka, 7 - 10 December 2010.

Soeini, R.A., Tashakor, L., Bafghi, J.T., Mokhtari, M., \& Vakili, A. (2012). Supplier selection based on multiple criteria. International Journal on New Computer Architectures and Their Applications, 2(1), 258-273.

Tahriri, F., Osman, Md. R., Ali, A., \& Yusuff, R. Md., (2008), A Review of Supplier Selection Methods in Manufacturing Industries, Suranaree Journal of Science \& Technology, 15(3),201-208.

Ting, S.-C. (2004). A multi-objective approach to supplier selection and purchasing decision in the supply chain, MCDM 2004, Whistler, B. C. Canada.

Trewatha, R.L., \& Newport, M.G. (1982). Management. $3^{\text {rd }}$ ed., Business Publications, 1982 ,

Triantaphyllou, E., Shu, B., Nieto Sanchez, S., \& Ray, T. (1998). Multi-criteria decision making: An operations research approach. Encyclopedia of Electrical and Electronics Engineering, 15, 175-186.

Tsai, C.-H., Chang, C.-L., \& Chen, L. (2003). Applying grey relational analysis to the vendor evaluation model. International Journal of The Computer, The Internet and Management, 11(3), 45-53.

Turskis, Z., \& Zavadskas, E. K. (2010a). A novel method for multiple criteria analysis: Grey additive ratio assessment (ARAS-G) Method, Informatica, 21(4), 597-610.

Turskis, Z. \& Zavadskas, E.K. (2010b). A new fuzzy additive ratio assessment method (ARAS-F). Case Study: The analysis of fuzzy multiple criteria in order to select the logistic centers location, Transport, 25(4), 423-432.

Turskis, Z., Zavadskas, E.K., \& Kutut, V. (2013). A model based on ARAS-G and AHP methods for multiple criteria prioritizing of heritage value. International Journal of Information Technology \& Decision Making, 12(1), 45-73.

Vahdani, B., Alem-Tabriz, A., \& Zandieh, M. (2009). Vendor selection: An enhanced hybrid fuzzy MCDM model. Journal of Industrial Engineering, 2, 231-239.

Yang, J.L., Chiu, H.N., Tzeng, G.-H., \& Yeh, R.H. (2008). Vendor selection by integrated fuzzy MCDM techniques with independent and interdependent relationships. Information Sciences, 178, 4166-4183.

Zadeh, L.A. (1965). Fuzzy sets, Information and Control, 8, 338-353.

Zagorskas, J., Burinskienė, M., Zavadskas, E., \& Turskis, Z. (2007). Urbanistic assessment of city compactness on the basis of GIS applying the COPRAS method. Ekologija. 53. 55-63.

Zavadskas, E.K. \& Turskis, Z. (2008). A new logarithmic normalization method in games theory. Informatica, 19(2), 303-314.

Zavadskas, E. K.; Turskis, Z., (2010), A new additive ratio assessment (ARAS) method in multicriteria decision-making, Technological and Economic Development of Economy, 16(2),159-172. 
Zavadskas, E.K., \& Kaklauskas, A. (1996). Determination of an efficient contractor by using the new method of multicriteria assessment, in Langford, D. A., Retik, A. (Eds.), International Symposium for "The Organisation and Management of Construction". Shaping Theory and Practice. 94-104. 